Illinois State University

ISU ReD: Research and eData

Theses and Dissertations

3-20-2015

\title{
The effect of self-adherent tape and lace up ankle braces on ankle range of motion and dynamic balance in collegiate football players
}

Kristin Willeford

Illinois State University, kmwille@ilstu.edu

Follow this and additional works at: https://ir.library.illinoisstate.edu/etd

Part of the Kinesiology Commons

\section{Recommended Citation}

Willeford, Kristin, "The effect of self-adherent tape and lace up ankle braces on ankle range of motion and dynamic balance in collegiate football players" (2015). Theses and Dissertations. 370.

https://ir.library.illinoisstate.edu/etd/370

This Thesis is brought to you for free and open access by ISU ReD: Research and eData. It has been accepted for inclusion in Theses and Dissertations by an authorized administrator of ISU ReD: Research and eData. For more information, please contact ISUReD@ilstu.edu. 


\title{
THE EFFECT OF SELF-ADHERENT TAPE AND LACE UP ANKLE BRACES ON ANKLE RANGE OF MOTION AND DYNAMIC BALANCE IN COLLEGIATE FOOTBALL PLAYERS
}

\author{
Kristin M. Willeford
}

32 Pages

May 2015

Context: Ankle sprains are one of the most common injuries in the physically active population. Previous research has shown that supporting the ankle with taping or bracing methods is effective at preventing ankle sprains. However, no research exists on the effects of self-adherent tape and lace up ankle braces on the restriction of range of motion and dynamic balance in collegiate football players. Objective: To examine the effectiveness of self-adherent tape and lace up ankle braces in reducing ankle range of motion and improving dynamic balance before and after a typical collegiate football practice. Design: Crossover. Setting: Athletic Training Room. Participants: Twentynine division I football athletes (age 19.2 $\pm 1.14 \mathrm{yrs}$, height $187.52 \mathrm{~cm} \pm 20.54$, mass $106.44 \mathrm{~kg} \pm 20.54)$. Interventions: Each participant wore each prophylactic ankle support condition during a single practice; self-adherent tape on one leg and lace up ankle brace on the other. Range of motion and dynamic balance were assessed three times on each leg throughout the testing session (baseline, pre-practice, post-practice). Main Outcome Measures: Range of motion (ROM) was assessed using a goniometer. The composite score for the Y-Balance test was used to quantify dynamic balance. Results: There were 
no significant differences between the tape and brace conditions in range of motion $(p=.10)$ or dynamic balance $(p=.83)$. Conclusion: Both the self-adherent tape and lace up ankle brace provided equal ROM restriction before and after exercise with no change in dynamic balance. Key Words: Self-Adherent Tape, Lace up Ankle Brace, Y Balance Test, Range of Motion. 
THE EFFECT OF SELF-ADHERENT TAPE AND LACE UP ANKLE BRACES ON ANKLE RANGE OF MOTION AND DYNAMIC BALANCE IN COLLEGIATE FOOTBALL PLAYERS

KRISTIN M. WILLEFORD

A Thesis Submitted in Partial Fulfillment of the Requirements for the Degree of

MASTER OF SCIENCE

School of Kinesiology and Recreation

ILLINOIS STATE UNIVERSITY

2015 
(C) 2015 Kristin M. Willeford 
THE EFFECT OF SELF-ADHERENT TAPE AND LACE UP ANKLE BRACES ON ANKLE RANGE OF MOTION AND DYNAMIC BALANCE IN COLLEGIATE FOOTBALL PLAYERS

KRISTIN M. WILLEFORD

COMMITTEE MEMBERS:

Justin M. Stanek, Chair

Todd McLoda, Co-Chair 


\section{ACKNOWLEDGMENTS}

I would like to thank my committee, Drs. Justin Stanek and Todd McLoda, who guided me through the entire process. Thank you to Wendy Williams for her assistance with data collection. Finally, I would like to thank the Illinois State University football team for volunteering to participate in the research study.

K.W. 


\section{CONTENTS}

Page

ACKNOWLEDGMENTS $\quad$ i

$\begin{array}{ll}\text { CONTENTS } & \text { ii }\end{array}$

$\begin{array}{ll}\text { TABLES } & \text { iii }\end{array}$

FIGURES

CHAPTER

I. INTRODUCTION 1

II. REVIEW OF RELATED LITERATURE 4

Anatomy $\quad 4$

Etiology and Prevalence of Ankle Sprain $\quad 10$

$\begin{array}{ll}\text { Prevention } & 12\end{array}$

$\begin{array}{ll}\text { Dynamic Balance } & 14\end{array}$

$\begin{array}{ll}\text { III. METHODS } & 16\end{array}$

$\begin{array}{ll}\text { Participants } & 16\end{array}$

$\begin{array}{ll}\text { Procedures } & 16\end{array}$

$\begin{array}{ll}\text { Range of Motion Testing } & 17\end{array}$

$\begin{array}{ll}\text { Dynamic Balance } & 18\end{array}$

Taping and Bracing $\quad 19$

$\begin{array}{ll}\text { Statistical Analysis } & 21\end{array}$

$\begin{array}{ll}\text { IV. RESULTS } & 22\end{array}$

V. DISCUSSION AND CONCLUSION 26

Discussion $\quad 26$

Conclusion 29

$\begin{array}{ll}\text { REFERENCES } & 30\end{array}$ 


\section{TABLES}

Table $\quad$ Page

1. Inversion Range of Motion 23

2. Eversion Range of Motion 23

3. Dorsiflexion Range of Motion 23

4. Plantar flexion Range of Motion 24

5. Dynamic Balance - Anterior Reach 24

6. Dynamic Balance - Posteromedial Reach 24

7. Dynamic Balance - Posterolateral Reach 25 


\section{FIGURES}

Figure $\quad$ Page

1. Taping and Bracing Condition 20

2. Lower Quarter Y-balance Test ${ }^{\mathrm{TM}} \quad 20$ 


\section{CHAPTER I}

\section{INTRODUCTION}

Ankle ligament injury accounts for $15 \%$ of all athletic injuries with $85 \%$ of these injuries involving the lateral ankle ligament complex. ${ }^{1}$ The NCAA injury surveillance system reported more than 27,000 ankle ligament sprains from 1988-2004 throughout 16 NCAA sanctioned sports. ${ }^{2}$ Athletic movements such as planting, cutting and jumping often force the ankle into plantar flexion and inversion, the common mechanism for lateral ankle sprain. The degree of ankle sprain injury ranges from micro tears to complete rupture of the involved ligaments which can result in long term pain and dysfunction.

The high incidence and lingering symptoms of ankle sprains have led sports medicine professionals to utilize taping and bracing as a preventative tool for injury. In one study, incidence of ankle sprain decreased from 32.8 to 14.7 per 1000 exposures with the implementation of prophylactic ankle taping. ${ }^{3}$ White cloth tape has been traditionally used within sports medicine settings to decrease ankle range of motion and provide external support. Numerous investigators have shown that white tape loosens with activity, reducing the effectiveness of the prophylactic taping. ${ }^{4-8}$ Fumich et $\mathrm{al}^{9}$ reported a $50 \%$ decrease in the restrictive properties of white athletic tape after a 2.5 hour football practice when compared to before practice.

Various types of ankle braces have also been developed and utilized as an 
alternative prevention tool. Paris et al ${ }^{4}$ compared a lace up brace and subtalar brace to traditional taping and found both braces provided greater support throughout activity than tape. Rovere et $\mathrm{al}^{10}$ compared ankle taping to laced ankle stabilizers in the prevention of ankle injury over six seasons of collegiate football. Results of the study showed a $50 \%$ decrease in ankle injury with the use of laced ankle stabilizers.

A new taping product was recently developed to address the support flaws of white athletic tape. Self-adherent tape and prewrap are highly moldable and alleged to maintain restriction throughout activity. ${ }^{11}$ Knight et al. ${ }^{12}$ found no significant difference between self-adherent tape and cloth tape before or after exercise. In contrast, Purcell et $\mathrm{al}^{6}$ found self-adherent tape provided greater restriction than cloth tape before and after 30 minutes of exercise. No published studies comparing self-adherent tape to ankle braces were found, and studies of the benefits of self-adherent tape were not conducted for more than 30 minutes of exercise. It is important to identify the amount of support provided by these two prophylactic devices before and after sport specific activity to aid in the prevention of ankle injury.

Dysfunctional single leg dynamic balance has been identified as a risk factor for injury in athletics and is associated with elevated risk of lower extremity non-contact injury in collegiate football players. ${ }^{13-17}$ Plisky et al ${ }^{13}$ observed an elevated lower extremity injury risk with poor performance on dynamic balance testing. The relationship between type of ankle support and dynamic balance has not been established in American football athletes. Therefore, the purpose of our study was to examine the effectiveness of self-adherent tape and lace up ankle braces in reducing ankle range of 
motion and improving dynamic balance before and after a typical collegiate football practice. 


\section{CHAPTER II}

\section{REVIEW OF RELATED LITERATURE}

\section{Anatomy}

The foot and ankle complex is composed of 26 bones and sesamoids. ${ }^{18,19}$ The tibia and fibula are long bones that make up the lower leg. The tibia is the main weight bearing bone of the lower leg and its most distal end forms the medial malleolus which serves as an attachment sight for medial ankle ligaments. The distal end of the fibula forms the lateral malleolus which serves as an attachment sight for many lateral ankle ligaments. Seven tarsal bones are aligned in proximal and distal rows in the foot. ${ }^{19}$ The most proximal tarsal bone, the talus, articulates with the medial malleoli to form a connection between the lower leg and foot thus making up the "ankle" (talocrural) joint. ${ }^{19}$

Below the talus lies the subtalar joint (talocalcaneal joint) where the talus meets the calcaneus. ${ }^{19}$ The calcaneus is the largest of the tarsal bones ${ }^{18}$ and serves as an attachment sight for muscles and ligaments in the lower leg, ankle, and foot. The distal tarsal bones include the navicular, three cuneiforms, and cuboid. ${ }^{19}$ The navicular is the most medial tarsal bone and articulates proximally with the talus and distally with the cuneiform bones. ${ }^{18}$ The navicular serves as an attachment sight for medial ankle ligaments and muscles. The medial cuneiform articulates proximally with the navicular and distally with the base of the $1^{\text {st }}$ metatarsal (long bone in the base of the foot). ${ }^{18}$ The 
intermediate cuneiform articulates proximally with the navicular and distally with the base of the $2^{\text {nd }}$ metatarsal. ${ }^{18}$ The lateral cuneiform articulates proximally with the navicular and distally with the base of the $3^{\text {rd }}$ metatarsal. These three bones are connected by strong interosseous ligaments and help shape the transverse arch of the foot. ${ }^{18}$ The cuboid is the most lateral tarsal bone in the distal row and articulates proximally with the calcaneus and distally with the $4^{\text {th }}$ and $5^{\text {th }}$ metatarsals. ${ }^{19}$

The forefoot contains fourteen phalanges and five connecting metatarsal bones. ${ }^{19}$ The metatarsals are a group of long bones located distal to the tarsal bones. The first metatarsal is the shortest and thickest of the group with two sesamoid bones located under the distal end (head). ${ }^{18}$ The first, second, and third metatarsal bones articulate with the three cuneiform bones while the fourth and fifth metatarsals articulate with the cuboid bone. Each toe is made up of three bony segments (phalanges); proximal, middle, and distal. The big toe (hallux) is composed of only two bony segments; proximal and distal, and is the primary weight bearing phalanx. ${ }^{18}$

The foot and ankle complex also contain many stabilizing ligaments. The primary medial ligaments of the ankle include the deltoid ligament and the plantar calcaneonavicular (spring) ligament. ${ }^{19}$ The deltoid ligament is a strong, triangular shaped ligament composed of anterior, intermediate, and posterior fibers. ${ }^{18}$ The anterior fibers originate at the medial malleolus and insert on the navicular tuberosity. These ligament fibers help to limit plantar flexion. ${ }^{18}$ The intermediate fibers originate on the apex of the medial malleolus and insert on the sustentaculum tali of the calcaneus. ${ }^{18}$ The posterior fibers originate on the posterior aspect of the medial malleolus and insert on the medial talar tubercle. These ligament fibers help to limit dorsiflexion. ${ }^{18}$ Also located on the 
medial side of the ankle is the plantar calcaneonavicular (spring) ligament. This ligament originates on the sustentaculum tali of the calcaneus and inserts on the plantar surface of the navicular. ${ }^{18}$ These ligaments are damaged when the ankle is forced into eversion and dorsiflexion.

The primary lateral ligaments of the ankle include the anterior talofibular ligament, posterior talofibular ligament, and the calcaneofibular ligament. The anterior talofibular ligament (ATFL) originates on the anterior portion of the lateral malleolus and inserts on the anterior talus. ${ }^{18}$ This ligament limits anterior displacement of the ankle and helps to limit plantar flexion. ${ }^{19}$ The posterior talofibular ligament (PTFL) originates from the distal lateral malleolus and inserts on the posterior talar process. This ligament aids in resisting posterior displacement of the ankle. ${ }^{18}$ The calcaneofibular ligament (CFL) originates on the apex of the lateral malleolus and inserts on the lateral calcaneal surface. ${ }^{18}$ This ligament assists the PTFL in resisting posterior displacement of the ankle and assists the posterior fibers of the deltoid ligament in limiting dorsiflexion. ${ }^{18}$ These ligaments are frequently damaged when the ankle is placed into forced inversion and plantar flexion.

The interosseous membrane, located between the tibia and fibula, aids in lower leg support by preventing movement between the tibia and fibula. ${ }^{18}$ Syndesmosis ligaments also connect the tibia and fibula which include anterior-inferior tibiofibular ligament, posterior-inferior tibiofibular ligament, interosseous ligament, and inferior transverse tibiofibular ligament. ${ }^{20}$ The anterior-inferior tibiofibular ligament is a strong ligament that originates on the lateral malleolus and inserts on the anterolateral tibia. ${ }^{18}$ This ligament prevents excessive fibular movement and talar rotation. ${ }^{20}$ The posterior- 
inferior tibiofibular ligament fibers originate on the posterior tubercle of the tibia insert on the posterior lateral malleolus. This ligament prevents widening between the distal tibia and fibula. ${ }^{20}$ The interosseous ligament originates at the medial aspect of the distal fibula and inserts on the lateral surface of the distal tibia. ${ }^{18}$ The inferior transverse tibiofibular ligament originates at the distal posterior tibia and inserts on the medial distal fibula. ${ }^{18}$ This ligament deepens the ankle mortise and prevents posterior talar movement. ${ }^{20}$

Movement at the ankle and foot is possible with the numerous muscles and tendons that act on the joint. The tibialis anterior originates on the lateral tibial condyle, interosseous membrane, proximal $2 / 3$ of anterolateral tibia, anterior intermuscular septum and crural fascia in the proximal lower leg and inserts on the medial and plantar surfaces of the $1^{\text {st }}$ metatarsal and cuneiform. ${ }^{18}$ This muscle is the primary dorsiflexor of the ankle and assists in inversion and adduction of the foot. ${ }^{19}$ The extensor hallucis longus originates on the medial aspect of the fibula, interosseous membrane and crural fascia and inserts on the dorsal surface of the proximal and distal phalanx of the hallux. ${ }^{18}$ This muscle extends the distal phalanx of the hallux and assists in dorsiflexion, inversion and adduction. ${ }^{19}$ The extensor digitorum longus originates on the lateral condyle of the tibia, upper anterior surface of the fibula, interosseous membrane and crural fascia and inserts via 4 tendons to the dorsal surface of the middle and distal phalanx of the $2^{\text {nd }}$ through $5^{\text {th }}$ rays. This muscle extends the lateral 4 toes and assists in dorsiflexion and eversion. ${ }^{18}$ Peroneus tertius originates on the distal $1 / 3$ of the anterior fibula and inserts on the dorsal surface of the base of the $5^{\text {th }}$ metatarsal. ${ }^{18}$ This muscle assists with dorsiflexion and eversion. ${ }^{19}$ 
The tibialis posterior originates on the posterior proximal tibia, medial surface of the fibula and interosseous membrane, it inserts on the navicular tuberosity, all three cuneiforms, cuboid, sustentaculum tali, and the base of the $2^{\text {nd }}$ through $4^{\text {th }}$ metatarsals..$^{18}$ This muscle stabilizes the ankle, aids in inversion, plantar flexion, adduction, and prevents hyper pronation when walking. ${ }^{18}$ The flexor digitorum longus originates on the posterior surface of the tibia and crural fascia while inserting on the plantar surface of the base of the $2^{\text {nd }}$ through $5^{\text {th }}$ distal phalanges. This muscle primarily flexes the $2^{\text {nd }}$ through $5^{\text {th }}$ toes but also assists in plantar flexion, inversion, and adduction of the foot. ${ }^{18}$ The flexor digitorum brevis originates on the medial calcaneus and plantar aponeurosis while inserting on the bases of the $2^{\text {nd }}$ through $5^{\text {th }}$ middle phalanx. ${ }^{18}$ This muscle flexes toes 2 through $5 .{ }^{19}$ The flexor hallucis longus originates on the posterior-inferior $2 / 3$ of the fibula, interosseous membrane, crural fascia and posterior intermuscular septum while inserting on the plantar surface of the distal phalanx of the hallux. ${ }^{18}$ This muscle flexes the hallux and aids in plantar flexion, inversion, and adduction of the foot. ${ }^{19}$ The flexor hallucis brevis originates on the medial aspect of the cuboid and lateral cuneiform while inserting on the medial and lateral base of the proximal phalanx of the hallux. ${ }^{18}$ This muscle flexes the hallux. ${ }^{19}$

Behind the lateral malleolus lie the tendons of peroneus longus and peroneus brevis. The peroneus longus originates on the head and proximal $2 / 3$ of the lateral fibula and inserts distally on the plantar surface of the cuboid, medial cuneiform, and base of the first and second metatarsal. ${ }^{18}$ The peroneus brevis originates on the distal $2 / 3$ of the lateral fibula and inserts via its tendon to the styloid process on the $5^{\text {th }}$ metatarsal. ${ }^{18}$ These 
muscles move the foot into the eversion and abduction and also act as weak plantarflexors. ${ }^{19}$

The posterior calf musculature includes the gastrocnemius, soleus and plantaris. Collectively these three muscles are known as the triceps surae. ${ }^{21}$ The gastrocnemius is the largest calf muscle which originates above the medial femoral condyle via its medial head and above the lateral femoral condyle via its lateral head. ${ }^{18}$ The gastrocnemius muscle belly runs parallel down the lower leg and inserts on the posterior calcaneus via the Achilles tendon. ${ }^{19}$ This muscle is the largest plantarflexor of the ankle and also assists in knee flexion during non-weight bearing knee movement. ${ }^{18}$ The soleus originates on the upper fibula and soleal line of the tibia. ${ }^{21}$ The soleus unites with the gastrocnemius via the Achilles tendon and inserts on the posterior calcaneus to assist in plantar flexion. ${ }^{18}$ The plantaris originates above the lateral head of the gastrocnemius on the femur with fibrous attachments within the calcaneal tendon and posteromedial calcaneus. ${ }^{21}$ This muscle acts in conjunction with the gastrocnemius and soleus to aid in plantar flexion. ${ }^{21}$

The foot is composed of three arches; medial longitudinal, lateral longitudinal, and transverse. ${ }^{19}$ The arches are created by the shape of the bones of the foot and are maintained by ligaments and muscles within the foot and ankle. The medial longitudinal arch is shaped by the calcaneus, talus, navicular, cuneiform, and the first three metatarsals. ${ }^{18}$ The main function of this arch is to provide shock absorption by "flattening" when pressure is applied. ${ }^{19}$ The lateral longitudinal arch is shaped by the calcaneus, cuboid and $4^{\text {th }}$ and $5^{\text {th }}$ metatarsals. ${ }^{18}$ The main function of this arch is to transmit and distribute body weight throughout the foot when a load is applied. ${ }^{19}$ The transverse arch is formed by the navicular, three cuneiforms, and the base of the five 
metatarsal bones. ${ }^{18}$ The three arches work together to support the weight of the body while providing cushion and leverage during gait.

Many movements occur in the foot and ankle to enable the joint to be so versatile. These movements include dorsiflexion, plantar flexion, inversion, eversion, pronation, supination, and gliding. Dorsiflexion occurs at the talocrural joint when the dorsum of the foot is moved upward (toes up). ${ }^{19}$ Plantar flexion also occurs at the talocrural joint when bending occurs in the direction of the plantar surface (point toes) ${ }^{19}$ Inversion occurs when the sole of the foot is moved inward (medially) while eversion occurs when the sole of the foot is moved outward (laterally). ${ }^{19}$ These motions occur mainly at the subtalar joint but gliding and rotation also occur at the talocalcaneonavicular joint. ${ }^{22}$

Plantar flexion must occur to achieve full inversion while dorsiflexion must occur to achieve full eversion. ${ }^{18}$ In weight bearing, pronation is a combination of abduction, calcaneal eversion, and plantar flexion. ${ }^{19}$ Supination is a combination of adduction, calcaneal inversion, and dorsiflexion during weight bearing movement. ${ }^{19}$ These motions occur at the subtalar joint and are important to allow proper cushion and leverage of the foot during gait. Gliding occurs when bones move side by side. This motion occurs between the tarsal and metatarsal bones. ${ }^{18}$

\section{Etiology and Prevalence of Ankle Sprain}

Ankle sprains occur when an excessive load is placed upon the ankle that cannot be compensated for by the joint or other stabilizing forces. Ankle sprains are classified into three grades based on severity of injury to the ligamentous structures. A grade one ligament sprain is classified by slight stretching of the involved ligament with no joint laxity present. ${ }^{19,23} \mathrm{~A}$ grade two ligament sprain is classified by partial tearing of the 
involved ligament, creating slight joint laxity. ${ }^{19,23}$ A grade three ligament sprain is classified by a complete tear of the involved ligament resulting in joint laxity and instability. ${ }^{19,23}$

The most common mechanism of injury is when the ankle is forced into inversion and plantar flexion placing stress on the lateral ankle ligament complex. ${ }^{19}$ The bony anatomy of the shorter medial malleolus adds to the natural tendency for the ankle to be placed in inversion, resulting in a lateral ankle sprain. ${ }^{1,19}$ In athletes, the lateral ankle ligaments are the most commonly injured structures in the body, accounting for $15 \%$ of all athletic injuries. ${ }^{1}$ Rovere et al ${ }^{10}$ tracked football ankle sprain injuries over a 7 year period and classified $87 \%$ as lateral ankle sprains. Due to the bony and ligamentous anatomy on the medial side of the ankle, medial ankle sprains only account for $5-10 \%$ of ankle sprains and occur when the ankle is forced into eversion and plantar flexion. ${ }^{19}$

Examination of the NCAA injury surveillance system from 1988-2004, revealed more than 27,000 ankle ligament sprains over the 16 year data collection period. ${ }^{2}$ Specifically, $13.6 \%$ of all football game injuries and $13.9 \%$ of all football practice injuries were classified as ankle ligament injuries. ${ }^{2}$ Unfortunately, a high prevalence of re-injury exists due to muscular weakness, instability, and damage to the proprioceptors within the ankle ligaments. ${ }^{24,25}$ Yeung et $\mathrm{al}^{26}$ reported a $73.5 \%$ recurrence rate for athletes to sprain the same ankle two or more times and a $22 \%$ recurrence rate of five or more sprains of the same ankle. An increase in residual symptoms such as pain, weakness, instability and stiffness increase as the quantity of ankle sprains rise. ${ }^{26,27}$ With the high prevalence and recurrence rate of ankle sprains, prevention strategies have been at the forefront of research for many years. 


\section{Prevention}

Prevention of ankle sprains requires an increase in ankle stability by both active and passive protective mechanisms. ${ }^{28}$ Active protection of the ankle is provided through activation of the surrounding musculature while passive protection is provided by bones, ligaments, and external ankle support devices. ${ }^{28}$ Although active protection of the ankle does occur, the length of time required for the musculature to respond is much too slow to protect the ankle from injury. ${ }^{28,29}$ Passive protection provided by external ankle support has been shown to decrease the occurrence of ankle sprains. ${ }^{1,10}$ External ankle support is used to limit range of motion at the extreme range where ankle ligament injury occurs without hindering normal function of the ankle. Garrick et $\mathrm{al}^{1}$ found the incidence of ankle sprains decreased from 32.8 to 14.7 per 1000 athlete exposures when ankle taping was utilized.

Although research has shown benefits of decreasing injury when using white athletic tape, several researchers have found that athletic tape loses its restrictive

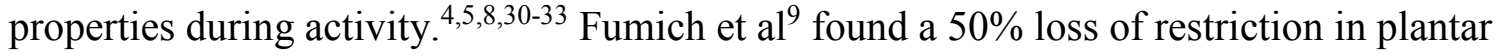
flexion, dorsiflexion, and eversion after a 2.5 to 3 hour football practice when using white athletic tape. In order to address the loosening properties of white athletic tape, other external ankle support devices such as braces and self-adherent tape were developed. ${ }^{6,12}$

Rovere et $\mathrm{al}^{10}$ tracked ankle injuries and re-injuries over six seasons of collegiate football and found athletes wearing lace up ankle braces had half the risk of injury over athletes wearing white athletic tape (0.42-0.85). Conflicting results have been published

on the restrictive properties of lace up ankle braces. ${ }^{4,8,30,34,35}$ Researchers have found that lace up ankle braces lose restrictive properties throughout exercise in a similar pattern to 
other prophylactic devices such as white athletic tape and other ankle braces. ${ }^{8,30}$ Metcalfe et $\mathrm{al}^{8}$ compared lace up ankle braces to white athletic tape with moleskin and found the prophylactics lost restrictive properties over time at a similar rate. Greene et al ${ }^{30}$ compared lace up braces to air stirrup and ankle ligament protector braces and found a significant reduction in ankle range of motion restriction after 20 minutes of exercise. In contrast, Paris et $\mathrm{al}^{4}$ found the lace up brace retained eversion and plantar flexion support after exercise but lost inversion support after 15 minutes.

Two research studies have been published comparing the restrictive properties of self-adherent tape and white athletic tape. ${ }^{6,12}$ Knight et al $^{12}$ found that self-adherent tape decreased ankle range of motion by $17 \%$ before exercise while white athletic tape decreased range of motion by $12 \%$ before exercise but no significant difference was found after exercise. The authors concluded self-adherent tape and white athletic tape were equally as effective at providing support to the ankle. ${ }^{12}$ In contrast, Purcell et al ${ }^{6}$ found self-adherent tape restricted motion to a greater extent than white athletic tape before and after 30 minutes of exercise. White athletic tape restricted eversion to inversion range of motion immediately after application but did not restrict range of motion after exercise. ${ }^{6}$

Mechanical failure of white athletic tape has been attributed to separation and tearing of the fibers caused by mechanical strain and moisture. ${ }^{8}$ Although never investigated in a laboratory setting, manufacturers of self-adherent tape claim this product is sweat resistant and contains less than $1 \%$ stretch contributing to greater stability. ${ }^{11}$ Manufacturers also claim self-adherent underwrap provides a $241 \mathrm{~b}$ increase in tensile 
strength as opposed to white athletic prewrap that provides no additional tensile strength. $^{36}$

\section{Dynamic Balance}

Just as restriction of ankle range of motion is key to preventing ankle injury, the ability to maintain balance during athletic movements such as running, jumping, and cutting is also critical to injury prevention. Dysfunctional single leg dynamic balance has been identified as a risk factor for injury. ${ }^{13-15}$ The star excursion balance test is a dynamic balance test uses eight reach directions to assess single leg dynamic balance. ${ }^{13,37,38}$ This test requires strength, flexibility, and proprioception. ${ }^{13}$ Low scores or asymmetry on the star excursion balance test has been shown to increase the risk of lower extremity injury. ${ }^{39,40}$ Anterior, posteromedial, and posterolateral reach directions have been found to be the greatest indicators of injury risk. ${ }^{17}$

The Y-balance test is a streamlined version of the star excursion balance test which measures lower extremity unilateral reach in three directions; anterior, posteromedial, and posterolateral. The Y-balance test kit is comprised of a single stance platform to which three pieces of PVC pipe are attached in the anterior, posteromedial, and posterolateral directions. The pipes create a Y shape as the two posterior pipes are located 135 degrees from the anterior pipe with 45 degrees between the two posterior pipes. Each pipe is marked in $5 \mathrm{~mm}$ increments and is equipped with a rectangular slide that can move down the PVC pipe with minimal effort. The trial does not count if: the subject failed to maintain unilateral stance (fell off center platform, touched down on floor with reach foot), failed to maintain contact with slide throughout motion (kicked), 
used the slide for stance support (foot on top of slide for balance), or failed to return the reach foot to starting position (per YBT protocol). ${ }^{36}$

Reach distance is measured by the point where the closest side of the slide (distal portion of the foot) reaches. The subject begins with three trials in the anterior direction with the right leg and repeats the anterior direction with the left leg. The subject then switches to posterior medial and posterolateral directions while alternating legs to minimize fatigue. ${ }^{17}$ Three trials in each direction are recorded with the maximum reach score in each direction used for analysis. ${ }^{39}$

The use of prophylactic ankle support devices limit normal ankle range of motion but do not disrupt the ability to maintain dynamic balance in a healthy population. ${ }^{38,41}$ Barkoukis et al ${ }^{41}$ compared dynamic balance in individuals when wearing prophylactic ankle devices and found no significant differences in dynamic balance. Dynamic balance assessments have also been used as a screening tool for injury risk. ${ }^{17,39,40}$

The National Athletic Trainers' Association position statement on ankle injury exhibits the need for continued research on prophylactic taping and bracing while focusing on prevention using balance and neuromuscular control. ${ }^{42}$ 


\section{CHAPTER III}

\section{METHODS}

\section{Participants}

Participants were recruited from the Illinois State University football team. All participants regularly wore prophylactic ankle support when participating in athletic activities. Participants were excluded if they reported a history of ankle or foot injury within the last 6 months, had been diagnosed with chronic ankle instability, and/or surgery to the ankle or foot within the last 12 months. Participants were also excluded from the study if they had a diagnosed metabolic disorder or were not currently participating in athletics due to other injury/illness. A total of 41 individuals volunteered to participate in the research study. Due to exclusion criteria (5 ankle injuries over last six months, 3 foot injuries over last six months, 1 foot surgery over last twelve months, 3 not participating due to other injury), 29 individuals participated in the research study (age $19.2 \pm 1.14 \mathrm{yrs}$, height $187.52 \mathrm{~cm} \pm 20.54$, mass $106.44 \mathrm{~kg} \pm 20.54)$. The university’s Institutional Review Board reviewed and approved the study prior to data collection.

\section{Procedures}

Each volunteer reported to the athletic training room before and after football practice for one testing session. Data was collected during 8 practices that were similar in structure, duration $(97.5 \pm 17.53 \mathrm{~min})$, and temperature $\left(1.61 \pm 5.49^{\circ} \mathrm{C}\right)$. Subjects signed an informed consent and completed the pre-participation questionnaire. Range of motion 
and dynamic balance were assessed three times on each leg throughout the testing session which included; baseline (before the tape/brace was applied), pretest (immediately after the tape/brace was applied), and posttest (immediately after football practice). Each participant wore each prophylactic ankle support condition during a single practice; selfadherent tape on one leg and lace up ankle brace on the other. Limb dominance was assessed by asking participants which leg they would use to kick a ball. The tape condition was applied to the randomized condition (dominant or non-dominant) and the lace up brace was applied to the opposite limb (Figure 1). Each condition had equal representation of ankle dominance throughout the study.

\section{Range of Motion Testing}

Each participant was positioned supine on an examination table with the knee fully extended and ankle unsupported off the end of the table. Active ankle range of motion (AROM) was assessed using a hand held goniometer in four directions (inversion, eversion, dorsiflexion, and plantar flexion). The participant was instructed to move in the direction of measurement as far as possible while a trained research assistant performed goniometer measurements. During inversion and eversion range of motion measurement, the fulcrum of the goniometer was centered over the talocrural joint while the stationary arm was centered over the long axis of the tibia and the movement arm was centered over the $2^{\text {nd }}$ metatarsal. ${ }^{22}$ During dorsiflexion and plantar flexion ROM measurement, the fulcrum of the goniometer was centered over the lateral malleolus while the stationary arm was aligned with the long axis of the fibula and the movement arm was parallel to the $5^{\text {th }}$ metatarsal. ${ }^{22}$ All range of motion measurements were assessed bilaterally by the 
same trained research assistant who was unaware of the research hypothesis and to group allocation.

\section{Dynamic Balance}

Following range of motion data collection, the subject's dynamic balance was assessed using the Lower Quarter Y-balance Test ${ }^{\mathrm{TM}}$ (Figure 2). The Y-balance test assesses dynamic balance through maintaining a single leg stance while reaching in three directions (anterior, posteromedial, and posterolateral) with the contralateral limb. ${ }^{17}$

When performing the Y-balance test, subjects were instructed to stand barefoot on the center of the stance platform with the most distal aspect of the foot touching the starting line. ${ }^{17,36}$ The subjects then pushed the reach indicator in the red target area as far as possible while maintaining balance on the contralateral limb. ${ }^{17,36,39}$ Each reach

direction was labeled with reference to the stance leg. Per Y-balance test protocol, ${ }^{17,36}$ the trial was unsuccessful if: the subject failed to maintain unilateral stance (fell off center platform or touched down on floor with reach foot), failed to maintain contact with the reach indicator throughout motion, used the reach indicator for stance support, or failed to return the reach foot to starting position. If the subject was unable to perform a successful trial over three attempts, an additional trial was performed until a successful reach was completed (maximum of six attempts). ${ }^{17}$ If the subject could not perform a successful trial in six attempts, the direction was recorded as a fail. ${ }^{17}$ Performance for three test trials were recorded in each direction and the recorded maximal reach in each direction was used for analysis. ${ }^{39}$

Subjects performed six practice trials on each leg in all three directions before formal testing began to control for learning effects. ${ }^{36,37}$ Three test trials were performed 
in the anterior direction with the right leg followed by 3 test trials in the anterior direction with left leg. ${ }^{17}$ The subject then performed alternating test trials in the posteromedial and posterolateral directions to minimize fatigue. ${ }^{17}$ The researcher was certified to collect $\mathrm{Y}$ Balance Test data through free online training. ${ }^{36}$

Lower extremity limb length was measured to normalize reach distance using a cloth tape measure. The subject was positioned supine and the researcher performed a Weber-Barstow maneuver ${ }^{43}$ to equalize the pelvis. Bilateral limb length was measured from the inferior aspect of the anterior superior iliac spine to the most distal aspect of the medial malleolus. ${ }^{17}$ The composite score for the Y-balance test was calculated for each limb $($ Composite Reach Score $=[($ maximum anterior reach + maximum posteromedial reach + maximum posterolateral reach $) /(3 *$ Limb Length $\left.){ }^{*} 100\right) .{ }^{17}$

\section{Taping and Bracing}

Tape was applied using a standard closed basket weave technique ${ }^{22}$ using the following procedure: 1) the ankle is placed in 90 degrees of dorsiflexion, 2) two heel and lace pads with a small amount of skin lubricant were applied to the ankle, one over the Achilles tendon and one over the anterior ankle joint, 3) Echo-flex ${ }^{\mathrm{TM}}$ pre-wrap was applied on a full stretch in a circular pattern from the midfoot to the base of the calf, 4) three anchor strips of self-adherent tape were applied at the base of the gastrocnemius, followed by 3 medial-to-lateral stirrups, 5) horseshoe strips were then placed from the base of the anchors to the malleolus, 6) two figure-eight strips and two heel locks (1 medial and 1 lateral) were placed continuously, 7) two anchor strips were placed at the base of the gastrocnemius and one anchor strip was placed at the midfoot. Self-adherent 
tape was applied by the same athletic trainer for all participants to control for taping variations.

Participants were given a new McDavid lace-up ankle brace (195T Ultralight) for testing. Ankle brace sizing was determined by the self-reported shoe size (Small: size 89, Medium: size 9-11, Large: size 11-13, Extra Large: size 14+) of the participant. The brace was applied by the participant over a single, new cotton, crew cut sock (ProFeet) in accordance with the manufacturer instructions. ${ }^{44}$ The brace was applied as follows: 1) lace as tightly as comfortable, 2) wrap one "figure- 8 " strap securely over the top of the foot, and up to the side of the foot and attach the Velcro patch, repeat with opposite strap, 3) attach cover strap at the top to secure ends of "figure-8" straps. ${ }^{44}$ An athletic trainer supervised the application of the brace to ensure proper fit.

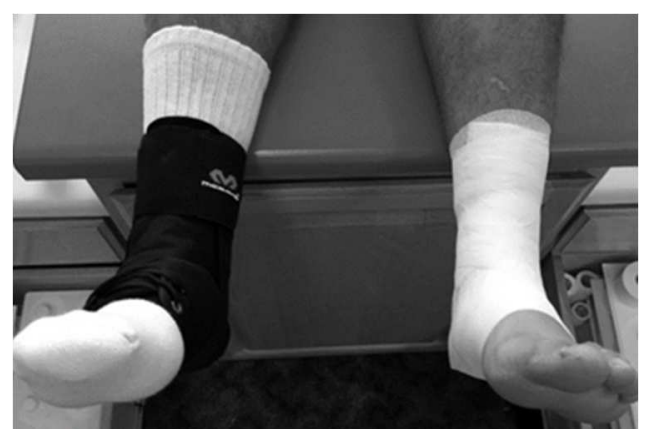

Figure 1. Taping and Bracing Condition

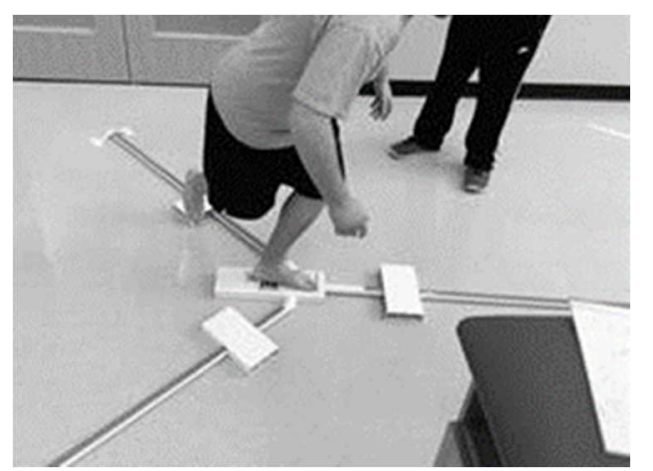

Figure 2. Lower Quarter Y-balance Test ${ }^{\mathrm{TM}}$ 
All volunteers participated in one collegiate football practice $(97.5 \mathrm{~min} \pm$ $17.53 \mathrm{~min}, 1.61^{\circ} \mathrm{C} \pm 5.49^{\circ} \mathrm{C}$ ) over the course of an eight day testing period. At the conclusion of practice, posttest ankle range of motion and dynamic balance measurements were assessed with the prophylactic device still on the ankle.

\section{Statistical Analysis}

An $\alpha$ level of $\mathrm{p} \leq .05$ was set to determine statistical significance a priori. A one way between groups multivariate analysis of variance (MANOVA) was performed to compare between groups differences. The independent variable was the type of intervention (self-adherent tape or brace) and the dependent variables included ankle range of motion and dynamic balance measurements. All data was analyzed using IBM SPSS version 21 software for Windows. 


\section{CHAPTER IV}

\section{RESULTS}

A one-way between groups MANOVA was performed to investigate range of motion differences between braced and taped individuals. Four dependent variables were used: inversion, eversion, plantar flexion, and dorsiflexion. Three levels of each dependent variable were analyzed: baseline, pre, and post. The independent variables were the condition: tape and brace. Preliminary assumption testing was conducted to check for normality, linearity, univariate and multivariate outliers, homogeneity of variance, and multicollinearity. Levene's test revealed a violation of assumption of equality of variance for the pre-plantar flexion variable $(p=.008 \leq .05)$. There were no statistically significant differences between groups, $\mathrm{F}(12,45)=1.7, \mathrm{p}=.10$, Wilks' Lambda $=.1 ;$ partial eta squared $=.311$.

Similarly, a one-way between groups MANOVA was performed to investigate dynamic balance differences in braced and taped individuals. Three dependent variables were used: anterior reach distance, posterior medial reach distance, and posterior lateral reach distance. Three levels of each dependent variable were analyzed: baseline, pre, and post. The independent variables were the condition: tape and brace. Preliminary assumption testing was again conducted with no violations noted. There was no 
statistically significant difference between groups, $\mathrm{F}(9,48)=.55, \mathrm{p}=.83$, Wilks' Lambda $=.997$; partial eta squared $=.093$.

Table 1. Inversion Range of Motion (degrees)

\begin{tabular}{ccccc}
\hline & N & Baseline & Pre-Practice & Post-Practice \\
\hline Self-Adherent Tape & 29 & $28.71 \pm 7.09$ & $20.28 \pm 6.57$ & $24.21 \pm 4.86$ \\
Lace Up Brace & 29 & $28.02 \pm 7.11$ & $17.38 \pm 4.59$ & $21.88 \pm 4.15$ \\
Total & 58 & $28.36 \pm 7.04$ & $18.82 \pm 5.80$ & $23.04 \pm 4.63$ \\
\hline
\end{tabular}

Table 2. Eversion Range of Motion (degrees)

\begin{tabular}{ccccc}
\hline & N & Baseline & Pre-Practice & Post-Practice \\
\hline Self-Adherent Tape & 29 & $6.67 \pm 3.15$ & $4.72 \pm 3.02$ & $6.43 \pm 2.83$ \\
Lace Up Brace & 29 & $6.43 \pm 3.46$ & $3.12 \pm 2.19$ & $5.69 \pm 2.34$ \\
Total & 58 & $6.55 \pm 3.28$ & $3.92 \pm 2.74$ & $6.06 \pm 2.60$ \\
\hline
\end{tabular}

Table 3. Dorsiflexion Range of Motion (degrees)

\begin{tabular}{ccccc}
\hline & $\mathrm{N}$ & Baseline & Pre-Practice & Post-Practice \\
\hline Self-Adherent Tape & 29 & $6.05 \pm 4.21$ & $0.52 \pm 4.02$ & $3.69 \pm 2.75$ \\
Lace Up Brace & 29 & $6.26 \pm 4.28$ & $0.64 \pm 3.21$ & $3.98 \pm 2.53$ \\
Total & 58 & $6.16 \pm 4.21$ & $0.58 \pm 3.61$ & $3.84 \pm 2.62$ \\
\hline
\end{tabular}


Table 4. Plantar flexion Range of Motion (degrees)

\begin{tabular}{ccccc}
\hline & N & Baseline & Pre-Practice & Post-Practice \\
\hline Self-Adherent Tape & 29 & $50.29 \pm 6.74$ & $43.84 \pm 7.62$ & $49.76 \pm 5.39$ \\
Lace Up Brace & 29 & $50.48 \pm 7.25$ & $41.52 \pm 4.95$ & $46.57 \pm 5.95$ \\
Total & 58 & $50.39 \pm 6.93$ & $42.68 \pm 6.47$ & $48.16 \pm 5.85$ \\
\hline
\end{tabular}

Table 5. Dynamic Balance - Anterior Reach (mm)

\begin{tabular}{ccccc}
\hline & $\mathrm{N}$ & Baseline & Pre-Practice & Post-Practice \\
\hline Self-Adherent Tape & 29 & $68.63 \pm 8.93$ & $65.30 \pm 9.62$ & $68.57 \pm 8.48$ \\
Lace Up Brace & 29 & $68.05 \pm 7.50$ & $65.84 \pm 9.95$ & $68.17 \pm 8.50$ \\
Total & 58 & $68.34 \pm 8.18$ & $65.57 \pm 9.70$ & $68.37 \pm 8.41$ \\
\hline
\end{tabular}

Table 6. Dynamic Balance - Posteromedial Reach (mm)

\begin{tabular}{ccccc}
\hline & N & Baseline & Pre-Practice & Post-Practice \\
\hline Self-Adherent Tape & 29 & $112.81 \pm 9.55$ & $111.06 \pm 9.96$ & $113.19 \pm 6.90$ \\
Lace Up Brace & 29 & $112.79 \pm 8.92$ & $112.01 \pm 8.34$ & $112.15 \pm 7.71$ \\
Total & 58 & $112.80 \pm 9.16$ & $111.54 \pm 9.12$ & $112.67 \pm 7.27$ \\
\hline
\end{tabular}


Table 7. Dynamic Balance - Posterolateral Reach (mm)

\begin{tabular}{ccccc}
\hline & N & Baseline & Pre-Practice & $\begin{array}{c}\text { Post- } \\
\text { Practice }\end{array}$ \\
\hline Self-Adherent Tape & 29 & $106.01 \pm 10.78$ & $107.23 \pm 10.04$ & $107.75 \pm 7.82$ \\
Lace Up Brace & 29 & $107.86 \pm 8.20$ & $106.64 \pm 10.43$ & $107.71 \pm 9.08$ \\
Total & 58 & $106.94 \pm 9.54$ & $106.94 \pm 10.15$ & $107.73 \pm 8.40$ \\
\hline
\end{tabular}




\section{CHAPTER V \\ DISCUSSION AND CONCLUSION}

\section{Discussion}

The purpose of this study was to examine the effectiveness of self-adherent tape and lace up ankle braces in reducing ankle range of motion and improving dynamic balance before and after a collegiate football practice. Our study is the first to examine the relationship between these two prophylactic devices in a collegiate football population.

Our results showed self-adherent tape and lace up ankle braces provided equal range of motion restriction before and after exercise while maintaining dynamic balance. While self-adherent tape has not previously been compared to lace up ankle braces, our range of motion results were similar to other investigators who have compared white athletic tape and various types of ankle braces. ${ }^{8,45}$ In contrast, other investigators have shown greater restriction of motion when utilizing ankle braces as compared to white athletic tape. ${ }^{4,5,30}$ Two studies have been conducted to examine ankle range of motion differences between self-adherent tape and white athletic tape before and after exercise. Knight et al ${ }^{12}$ found no significant difference in ankle inversion restriction before or after exercise. In contrast, Purcell et $\mathrm{al}^{6}$ found greater range of motion restriction in inversion to eversion range with self-adherent tape as compared to white athletic tape after 
exercise. Although the results of our research study cannot provide evidence for a reduction in ankle injury, many researchers agree that the use of prophylactic devices may be valuable in preventing ligament injury. ${ }^{5,32,33}$ Rovere et $a{ }^{10}$ conducted a six year retrospective research study to examine injury prevention as it relates to ankle braces and tape. This study found football athletes who wore lace up ankle braces reduced their risk of injury by half as compared to football athletes wearing white athletic tape.

Prevention strategies reach far beyond prophylactic ankle protection. The National Athletic Trainers' Association position statement on ankle injury focuses on using balance and neuromuscular control as a prevention strategy for ankle sprains. ${ }^{42}$ In sport, dynamic balance is needed for all athletic activity and dysfunctional dynamic balance is associated with elevated risk of lower extremity injury in collegiate football athletes. ${ }^{16,17}$ Our results showed self-adherent tape and lace up ankle bracing had no effect on dynamic balance which is consistent with the findings of other researchers utilizing a healthy patient population. ${ }^{38,41}$

With the cost of healthcare continuously rising, ankle sprain injury is critical to prevent due to the potential for long term disability. Yeung et $\mathrm{al}^{26}$ found an increase in residual symptoms such as pain, weakness, crepitus, instability, swelling, and stiffness as the number of ankle sprains increased in each ankle. This study found $9.4 \%$ of ankles with history of 1 sprain experienced residual symptoms and 37.9\% of ankles with a history of five or more sprains experienced residual symptoms. ${ }^{26}$ Staples et a ${ }^{46}$ reported only $58.7 \%$ of grade 3 ankle sprains completely recovered after 10 years. Hansen et al ${ }^{27}$ 
reported $20.8 \%$ of patients who suffered an ankle sprain experienced residual symptoms 3-3.6 years post injury.

Even with the high incidence of ankle sprain, the cost of prophylactic materials can play a large role in utilization of these products. Lace up braces (approximately $\$ 36.00$ in 2015) provide a cost effective alternative to self-adherent tape (approximately \$2.10 per application in 2015) and do not require trained personnel to apply.

The mean values for each group showed no statistical significance but provided clinical relevance as the mean range of motion values prior to and following activity were similar. In fact, this shows self-adherent tape provides as much restriction as a new lace up ankle brace and should be considered by health care professionals as an acceptable protective device to assist in managing the incidence or severity of ankle injury.

Two limitations were identified in this study. First, decreases in ankle range of motion and maintaining dynamic balance do not necessarily reduce the amount or severity of ankle sprains. Ankle ligament injury occurs when the ankle moves into extreme ranges of motion beyond the limits of the ligaments that provide static stability. The goal of applying prophylactic ankle braces or tape is to provide functional range of motion while preventing movement into the extreme limits of the static stabilizers. This, in turn, may reduce the incidence or severity of ankle injury. There may also be a benefit from the kinesthetic sense associated with the brace or tape application which is associated with injury prevention. ${ }^{47,48}$ This leads to the second limitation of the current study which was limited to football athletes who wear prophylactic ankle support on a daily basis. These results may not be generalizable to other athletic populations or to 
athletes who are first time wearers of ankle protection. The study design was strengthened by applying each prophylactic device to the same subject. This gave way to a true representation of the forces placed on the ankle during a typical collegiate football practice.

Future research needs to be conducted via a prospective multi-season study to determine the long term effects of prophylactic ankle devices and incidence of injury. We showed equal restriction in ankle range of motion with the self-adherent tape as compared to lace up ankle braces but this does not necessarily translate to prevention of injury. Future research also needs to investigate the mechanical properties of selfadherent tape and lace up ankle braces in an independent laboratory setting. The manufacturer of self-adherent tape suggests this product is waterproof and contains less than $1 \%$ stretch $^{6}$ but these values have not been verified in the laboratory setting. No published research has been conducted on the material breakdown of lace up ankle braces to establish guidelines for replacement. Additionally, self-adherent tape should be compared to other types of ankle braces to determine the best ankle protection device.

\section{Conclusion}

In conclusion, both the self-adherent tape and lace up ankle brace provided equal range of motion restriction before and after exercise with no change in dynamic balance. The decreased range of motion provided by the prophylactic devices allows the ankle to maintain neutral positioning therefore decreasing the chance of ligament injury. The use of these devices for ankle range of motion restriction would be an acceptable choice in the collegiate football setting. 


\section{REFERENCES}

1. Garrick JG. The frequency of injury, mechanism of injury, and epidemiology of ankle sprains. Am J Sports Med. 1977;5(6):241.

2. Hootman JM, Dick R, Agel J. Epidemiology of collegiate injuries for 15 sports: Summary and recommendations for injury prevention initiatives. $J$ Athl Train. 2007;42(2):311-319.

3. Garrick JG, Requa RK. Role of external support in the prevention of ankle sprains. Med Sci Sports. 1973;5(3):200-203.

4. Paris DL. Ankle ranges of motion during extended activity periods while taped and braced. J Athl Train. 1995;30(3):223.

5. Gross MT, Bradshaw MK, Ventry LC, Weller KH. Comparison of support provided by ankle taping and semirigid orthosis. J Orthop Sports Phys Ther. 1987;9(1):33-39.

6. Purcell SB, Schuckman BE, Docherty CL, Schrader J, Poppy W. Differences in ankle range of motion before and after exercise in 2 tape conditions. Am J Sports Med. 2009;37(2):383-389.

7. Greene TA, Hillman SK. Comparison of support provided by a semirigid orthosis and adhesive ankle taping before, during, and after exercise. Am J Sports Med. 1990;18(5):498-506.

8. Metcalfe RC, Schlabach GA, Looney MA, Renehan EJ. A comparison of moleskin tape, linen tape, and lace-up brace on joint restriction and movement performance. J Athl Train. 1997;32(2):136-140.

9. Fumich RM, Ellison AE, Guerin GJ, Grace PD. The measured effect of taping on combined foot and ankle motion before and after exercise. Am J Sports Med. 1981;9(3):165.

10. Rovere GD, Clarke TJ, Yates CS, Burley K. Retrospective comparison of taping and ankle stabilizers in preventing ankle injuries. Am J Sports Med. 1988;16(3):228.

11. Andover Healthcare Incorporated. http://www.andovercoated.com/sports/cohesive bandages.html. Published 2008. Accessed September 15, 2014.

12. Knight B, Oney J, Miller MG, Gyorkos A. Comparison of Self-Adherent and Cloth Tape on Dynamic Ankle Inversion Before and After Exercise. Athletic Training \& Sports Health Care. 2012;4(2):87.

13. Plisky PJ. Star Excursion Balance Test as a predictor of lower extremity injury in high school basketball players. J Orthop Sports Phys Ther. 2006;36(12):911.

14. Wang H. Risk-factor analysis of high school basketball-player ankle injuries: a prospective controlled cohort study evaluating postural sway, ankle strength, and flexibility. Arch Phys Med Rehabil. 2006;87(6):821. 
15. Trojian TH. Single leg balance test to identify risk of ankle sprains. Including commentary by Swenson EJ \& Grindel SH. Br J Sports Med. 2006;40(7):610.

16. de Noronha M, Franca LC, Haupenthal A, Nunes GS. Intrinsic predictive factors for ankle sprain in active university students: A prospective study. Scand J Med Sci Sports. 2013;23(5):541-547.

17. Plisky PJ. The reliability of an instrumented device for measuring components of the star excursion balance test. North American journal of sports physical therapy. 2009;4(2):92.

18. Gray H, Carter HV. Gray's anatomy / Henry Gray; drawings by H.V. Carter. New York : Barnes \& Noble; Lewes : GMC Distribution distributor, 2013; Classic illustrated ed; 2013.

19. Prentice WE, Arnheim D. Principles of athletic training : a competency-based approach / William E. Prentice. New York : McGraw-Hill Higher Education, 2011; 14th ed; 2011.

20. Norkus S. The Anatomy and Mechanisms of Syndesmotic Ankle Sprains. J Athl Train. 2001;36(1):68.

21. Spina A. The plantaris muscle: anatomy, injury, imaging, and treatment. The Journal of the Canadian Chiropractic Association. 2007;51(3):158.

22. Starkey C, Ryan JL. Evaluation of Orthopedic and Athletic Injuries. 2nd ed. Philadelphia, PA: F.A. Davis Co.; 2002.

23. Prado MP, Fernandes TD, Camanho GL, Mendes AAM, Amodio DT. Mechanical instability after acute ankle ligament injury: randomized prospective comparison of two forms of conservative treatment. Revista Brasileira de Ortopedia. 2013.

24. Freeman MA, Dean MR, Hanham IW. The etiology and prevention of functional instability of the foot. $J$ Bone Joint Surg Br. 1965;47(4):678-685.

25. Akbari M, Karimi H, Farahini H, Faghihzadeh S. Balance problems after unilateral lateral ankle sprains. $J$ Rehabil Res Dev. 2006;43(7):819-823.

26. Yeung MS, Chan KM, So CH, Yuan WY. An epidemiological survey on ankle sprain. Br J Sports Med. 1994;28(2):112-116.

27. Hansen H, Damholt V, Termansen NB. Clinical and Social Status Following Injury to the Lateral Ligaments of the Ankle Follow-up of 144 Patients Treated Conservatively. Acta Orthop Scand. 1979;50(6):699.

28. Alt W, Lohrer H, Gollhofer A. Functional properties of adhesive ankle taping: Neuromuscular and mechanical effects before and after exercise. Foot \& Ankle International. 1999;20(4):238-245.

29. Karlsson J, Andreasson GO. The effect of external ankle support in chronic lateral ankle joint instability: an electromyographic study. Am J Sports Med. 1992;20(3):257-261.

30. Greene TA, Wight CR. A comparative support evaluation of three ankle orthoses before, during, and after exercise. J Orthop Sports Phys Ther. 1990;11(10):453466.

31. Manfroy PP. The effect of exercise, prewrap, and athletic tape on the maximal active and passive ankle resistance of ankle inversion. Am J Sports Med. 1997;25(2):156. 
32. Pederson TS, Ricard MD, Merrill G, Schulthies SS, Allsen PE. The effects of spatting and ankle taping on inversion before and after exercise. J Athl Train. 1997;32(1):29-33.

33. Ricard MD, Sherwood SM, Schulthies SS, Knight KL. Effects of tape and exercise on dynamic ankle inversion. $J$ Athl Train. 2000;35(1):31-37.

34. Sharpe SR, Knapik J, Jones B. Ankle braces effectively reduce recurrence of ankle sprains in female soccer players. J Athl Train. 1997;32(1):21-24.

35. Shapiro MS, Kabo JM, Mitchell PW, Loren G, Tsenter M. Ankle sprain prophylaxis: an analysis of the stabilizing effects of braces and tape. Am J Sports Med. 1994;22(1):78-82.

36. www.ybalancetest.com. Updated 2013.

37. Hertel J. Intratester and Intertester During the Star Excursion Balance Tests. $J$ Sport Rehab. 2000;9(2):104.

38. Hardy L, Huxel K, Brucker J, Nesser T. Prophylactic ankle braces and Star Excursion Balance measures in healthy volunteers. J Athl Train. 2008;43(4):347-351.

39. Butler RJ, Lehr ME, Fink ML, Kiesel KB, Plisky PJ. Dynamic balance performance and noncontact lower extremity injury in college football players: an initial study. Sports Health. 2013;5(5):417-422.

40. McGuine TA. The effect of a balance training program on the risk of ankle sprains in high school athletes. Am J Sports Med. 2006;34(7):1103.

41. Barkoukis V, Sykaras E, Costa F, Tsorbatzoudis H. Effectiveness of taping and bracing in balance. Percept Mot Skills. 2002;94(2):566-574.

42. Kaminski TW, Hertel J, Amendola N, et al. National Athletic Trainers' Association Position Statement: Conservative Management and Prevention of Ankle Sprains in Athletes. J Athl Train. 2013;48(4):528.

43. Seidenberg PH, Bowen JD. The hip and pelvis in sports medicine and primary care. Hip and Pelvis in Sports Medicine and Primary Care. 2010.

44. McDavidUSA. www.mcdavidusa.com. Updated 2013. Accessed September 15, 2014.

45. Myburgh KH, Vaughan CL, Isaacs SK. The effects of ankle guards and taping on joint motion before, during, and after a squash match. Am J Sports Med. 1984;12(6):441.

46. Staples OS. Result study of ruptures of lateral ligaments of the ankle. Clin Orthop Relat Res. 1972;85:50-58.

47. Simoneau GG, Degner RM, Kramper CA, Kittleson KH. Changes in ankle joint proprioception resulting from strips of athletic tape applied over the skin. $J$ Athl Train. 1997;32(2):141-

48. Robbins S, Waked E, Rappel R. Ankle taping improves proprioception before and after exercise in young men. Br J Sports Med. 1995;29(4):242-247. 